\title{
SCIENTIFIC REPORTS

\section{Insecticidal activity and biochemical composition of Citrullus colocynthis, Cannabis indica and Artemisia argyi extracts against cabbage aphid (Brevicoryne brassicae L.)}

\author{
Maqsood Ahmed ${ }^{1,5}$, Qin Peiwen ${ }^{1 *}$, Zumin Gu ${ }^{1}$, Yuyang Liu ${ }^{1}$, Aatika Sikandar ${ }^{1,5}$, \\ Dilbar Hussain ${ }^{4}$, Ansar Javeed ${ }^{2,5}$, Jamil Shafi ${ }^{3}$, Mazher Farid Iqbal ${ }^{2}$, Ran An ${ }^{1}$, Hongxia Guo ${ }^{1}$, \\ Ying Du ${ }^{1}$, Weijing Wang ${ }^{1}$, Yumeng Zhang ${ }^{1}$ \& Mingshan $\mathrm{Ji}^{1 *}$
}

Plant extracts contain many active compounds, which are tremendously fruitful for plant defence against several insect pests. The prime objectives of the present study were to calculate the extraction yield and to evaluate the leaf extracts of Citrullus colocynthis (L.), Cannabis indica (L.) and Artemisia argyi (L.) against Brevicoryne brassicae and to conduct biochemical analysis by gas chromatography-mass spectrometry (GC-MS). The results suggested that when using ethanol, $C$. colocynthis produced a high dry yield (12.45\%), followed by that of $C$. indica and $A$. argyi, which were $12.37 \%$ and $10.95 \%$, respectively. The toxicity results showed that $A$. argyi was toxic to $B$. brassicae with an $\mathrm{LC}_{50}$ of $3.91 \mathrm{mg} \mathrm{mL}^{-1}$, followed by the toxicity of $C$. colocynthis and $C$. indica, exhibiting $\mathrm{LC}_{50}$ values of 6.26 and $10.04 \mathrm{mg} \mathrm{mL}^{-1}$, respectively, which were obtained via a residual assay; with a contact assay, the $L C_{50}$ values of $C$. colocynthis, $C$. indica and $A$. argyi were $0.22 \mathrm{mg} \mathrm{mL}^{-1}, 1.96$ and $2.87 \mathrm{mg} \mathrm{mL}^{-1}$, respectively. The interaction of plant extracts, concentration and time revealed that the maximum mortality based on a concentration of $20 \mathrm{mg} \mathrm{L}^{-1}$ was $55.50 \%$, the time-based mortality was $55 \%$ at $72 \mathrm{~h}$ of exposure, and the treatment-based mortality was $44.13 \%$ for $A$. argyi via the residual assay. On the other hand, the maximum concentration-based mortality was $74.44 \%$ at $20 \mathrm{mg} \mathrm{mL}^{-1}$, the time-based mortality was $66.38 \%$ after $72 \mathrm{~h}$ of exposure, and $57.30 \%$ treatment-based mortality was afforded by $A$. argyi via the contact assay. The biochemical analysis presented ten constituents in both the $A$. argyi and $C$. colocynthis extracts and twenty in that of C. indica, corresponding to $99.80 \%, 99.99 \%$ and $97 \%$ of the total extracts, respectively. Moreover, the detected caryophylleneonides (sesquiterpenes), $\alpha$-bisabolol and dronabinol ( $\Delta^{9}$-THC) from C. indica and erucylamide and octasiloxane hexamethyl from $C$. colocynthis exhibited insecticidal properties, which might be responsible for aphid mortality. However, $A$. argyi was evaluated for the first time against $B$. brassicae. It was concluded that all the plant extracts possessed significant insecticidal properties and could be introduced as botanical insecticides after field evaluations.

The cabbage aphid, Brevicoryne brassicae L. (Hemiptera: Aphididae), is a serious pest native to Europe but now found globally ${ }^{1,2}$, and it causes significant losses to economically important crops, including broccoli, oilseed rape, brussels sprouts, cauliflower, black and white mustard, toria, Chinese cabbage, kale, and other field crops ${ }^{1}$. It also causes yellowing, stunting, and plant wilting and acts as a vector of several viral diseases in crucifers, including cauliflower mosaic virus and turnip mosaic virus ${ }^{3,4}$. In the case of severe infestation, plants become covered with aphids, resulting in leaf surfaces roofed with black mould due to honey secretion, which can ultimately cause

${ }^{1}$ College of Plant Protection, Shenyang Agricultural University, Shenyang, 110866, P.R. China. ${ }^{2}$ College of Biosciences and Biotechnology, Shenyang Agricultural University, Shenyang, 110866, P.R. China. ${ }^{3}$ Department of Plant Pathology, University of Agriculture, Faisalabad, Sub-Campus Depalpur, Okara, 56300, Pakistan. ${ }^{4}$ Entomological Research Institute, Ayub Agricultural Research Institute, Faisalabad, 38040, Pakistan. ${ }^{5}$ These authors contributed equally: Maqsood Ahmed, Aatika Sikandar and Ansar Javeed. *email: qinpeiwen08@sina.com; jimingshan@163.com 
plant death ${ }^{5-7}$. Synthetic chemical insecticides are available sources for controlling this destructive pest, which is a key success for modern agricultural practices and enhances crop yield. However, indiscriminate use of synthetic pesticides for crop production and protection poses poisonous effects through contact, inhalation, and dietary exposure and has become a cause of carcinogenesis, fertility problems and mutagenesis in humans ${ }^{8-11}$.

These circumstances led towards searching for effective and eco-friendly pest control alternatives, especially from natural plant resources ${ }^{12}$. Many insecticides derived from botanical sources are available and are easily affordable and accessible to the farming community; they are safer for human beings and for the environment with minimal residual effect, and they are target-specific and less toxic to vertebrates, pollinators and fish ${ }^{13-17}$. Studies have demonstrated the aphicidal activity of Chenopodium ficifolium extracts and its isolated phospholipids, the alkaloids from Corydalis turtschaninovii tubers and Macleaya cordata seeds, the oil from Jatropha curcas and rhamnolipid from Pseudomonas species ${ }^{18-20}$. Other plant-based products, such as Melia azedarach seed extracts, Lantana camorra leaf and seed extracts and Mentha piperita leaf extracts, possess promising insecticidal properties against $B$. brassicae $e^{21-23}$.

Therefore, Citrullus colocynthis (Cucurbitaceae), Cannabis indica (Cannabaceae) and Artemisia argyi (Asteraceae) were selected for the present study, as they have been reported as having insecticidal potential against different stored grains and other field crop pests. The selected plants also possess a natural ability to deter insect attack. Among them, Cannabis has been reported as a repellent against vertebrates and invertebrates. It also showed better results when grown as a companion crop with other crops to prevent the infestation of weedy plants, fungi, insects and nematodes, while the extract from the dried leaves and flowers possess repellent and killing potential against the above-mentioned pests. However, pure cannabinoids extracted from this plants have been reported to kill or repel mites, insects, nematodes, fungi and protozoa ${ }^{24}$. Moreover, phytoconstituents analysis reported major terpenes, such as $\beta$-myrecene and $\beta$-caryophyllene, and the profusion of cannabidiolic acid (CBDA) and cannabidiol (CBD) from an extract of $C$. sativa (hemp) inflorescences by GC-MS, GC-FID and HPLC ${ }^{25}$. In a recent study, the activity of hemp essential oil from inflorescences was explored against Myzus persicae (Hemiptera), Culex quinquefasciatus (Diptera), Spodoptera littoralis (Lepidoptera) and Musca domestica (Diptera) and showed high toxicity against $M$. domestica and $M$. persicae, moderate toxicity against the larvae of S. littoralis and sparse toxicity against C. quinquefasciatus ${ }^{26}$.

Similarly, C. colocynthis has gained the attention of researchers as an alternative botanical insecticide, and the effectiveness of its extracts and isolated compounds has been assayed against economically important insect pest species. This plant showed antifeedant, deterrent and infertility activities against several pests ${ }^{27}$. The toxicity effects of $C$. colocynthis fruit, leaf, stem and root extracts were evaluated against Rhopalosiphum padi L. The results revealed the high effectiveness of the stem extract compared to that of the other part extracts against this pest $^{28}$. Moreover, the identified biocompounds from C. colocynthis fruits, i.e., 7,8-benzoquinoline, were the most efficient against Tetranychus urticae, while quinoline, 2-methylquinoline and 8-hydroxyquinoline were effective against Sitophilus zeamais and Sitophilus oryzae ${ }^{29}$.

As a medicinal plant, A. argyi, is generally known as Argyi wormwood or Chinese mugwort and is commonly found in China. Different Artemisia species are known for their pharmacological and insecticidal properties. The ethanol extracts from A. argyi possess a strong repellent effect against Drosophila melanogaster, which increased with increasing concentration and extended exposure time ${ }^{30}$. Furthermore, the bioactivity of isolated compounds from Artemisia judaica essential oil was evaluated against Spodoptera littoralis at the third larval instar, and against plant pathogenic fungi showed prominent insecticidal, antifeedant and antifungal activity. However, the antifeedant activity was concentration-dependent ${ }^{31}$. The antifungal activity of compounds isolated by GC-MS, such as $\beta$-thujone, $\alpha$-thujone, camphor, verbinol and davanone, showed high inhibition effects against Rhizoctonia solani, Fusarium solani, and Sclerotinia sclerotiorum whereas, exhibited slight effectiveness against Fusarium proliferatum and Fusarium oxysporum ${ }^{32}$.

Due to issues concerning the use of synthetic pesticides and the increasing resistance in pest species, pests can be managed by introducing botanical insecticides, especially against soft-bodied insects such as aphids. However, to our knowledge, few studies have been conducted regarding the aphicidal activity of the leaf extracts of $C$. colocynthis, C. indica and A. argyi against B. brassicae. To investigate safe alternatives for the management of this pest, the present study was conducted to evaluate the insecticidal effects of crude ethanol extracts of $C$. colocynthis, $C$. indica and $A$. argyi against the cabbage aphid B. brassicae by residual/leaf dip and contact/aphid dip bioassays under laboratory conditions at the Biopesticides Lab of Shenyang Agricultural University, P.R. China.

\section{Results}

Extract yield (dry weight \%). The extract yield obtained by solvent extraction using ethanol showed that in comparison, $(P<0.05)$, the extract yield afforded by C. colocynthis was $12.45 \%$, followed by that of $A$. argyi and $C$. indica (12.37\% and $10.95 \%)$ respectively. However, the extract yield produced by all the plant samples was not much different. The extract obtained from C. colocynthis and C. indica was sticky and fluidic in consistency with a brownish-black to blackish colour and a shiny in appearance. While, the extract from A. argyi was waxy in consistency with a yellowish-brown colour.

Toxicity of plant extracts on aphids. The mortality of $B$. brassicae was determined by using crude ethanol extracts from different plants under laboratory conditions by residual and contact assays. All botanical extracts exerted adverse effects against this pest at increasing concentrations and prolonged exposure periods.

Residual/leaf dip bioassay. The mortality data presented in Table S1 in the Supplementary File revealed the insecticidal activity of ethanol extracts from $C$. colocynthis, $C$. indica and $A$. argyi against $B$. brassicae. The percent mortality of $B$. brassicae was directly related to the concentration of the plant extracts and the exposure period. The results showed that the maximum mortality was recorded after $72 \mathrm{~h}$ of exposure to the A. argyi extract at 


\begin{tabular}{|c|c|c|c|c|c|c|}
\hline \multirow{2}{*}{$\begin{array}{l}\text { Plants } \\
\text { Extract }\end{array}$} & \multirow[b]{2}{*}{ Time (h) } & \multirow[b]{2}{*}{$\mathrm{LC}_{50}\left(\mathrm{mg} \mathrm{mL}^{-1}\right)$} & \multicolumn{2}{|c|}{ 95\% F.L. } & \multirow[b]{2}{*}{ Slope \pm SE } & \multirow[b]{2}{*}{$x^{2}$} \\
\hline & & & Lower & Upper & & \\
\hline \multirow{3}{*}{$\mathrm{CCL}$} & 24 & 466 & 64.1 & $1 . \mathrm{E} 20$ & $1.34 \pm 0.29$ & 0.17 \\
\hline & 48 & 68.1 & 28.3 & 340.7 & $0.76 \pm 0.25$ & 1.73 \\
\hline & 72 & 10.4 & 7.61 & 13.53 & $1.44 \pm 0.26$ & 6.52 \\
\hline \multirow{3}{*}{$\mathrm{CIL}$} & 24 & 273 & 59.4 & 597.7 & $0.76 \pm 0.31$ & 0.13 \\
\hline & \begin{tabular}{|l|}
48 \\
\end{tabular} & 36.4 & 18.8 & 414.0 & $0.78 \pm 0.25$ & 1.08 \\
\hline & 72 & 6.26 & 2.60 & 10.37 & $0.75 \pm 0.23$ & 0.09 \\
\hline \multirow{3}{*}{ ATL } & 24 & 38.6 & 24.4 & 114.5 & $1.31 \pm 0.29$ & 1.16 \\
\hline & 48 & 13.8 & 10.1 & 21.9 & $1.20 \pm 0.25$ & 1.03 \\
\hline & 72 & 3.91 & 2.66 & 5.07 & $1.67 \pm 0.26$ & 1.80 \\
\hline
\end{tabular}

Table 1. Toxicity against B. brassicae after an exposure of 24,48 and $72 \mathrm{~h}$ by the residual/leaf dip method. Note: $\mathrm{LC}_{50}$ (lethal concentrations); S.E. (standard error); $\chi^{2}$ (chi-square); F.L. (fiducial limit). *upper limits are greater than or equal to $1 . \mathrm{E} 20$ and are infinite values. CCL (C. colocynthis), CIL (C. indica) and ATL (A. argyi).

a concentration of $20 \mathrm{mg} \mathrm{mL}^{-1}$ and caused $88.33 \pm 3.87 \%$ mortality, while after $48 \mathrm{~h}$ of exposure, the mortality was recorded as $60.00 \pm 2.27 \%$. The mortality caused by $C$. indica after a $72 \mathrm{~h}$ and $48 \mathrm{~h}$ exposure period was $66.67 \pm 2.58 \%$ and $45.00 \pm 4.72 \%$, respectively, which were lower than those of $A$. argyi. However, the mortality caused by $C$. colocynthis was higher than that caused by $C$. indica after a $72 \mathrm{~h}$ exposure period $(76.67 \pm 1.29 \%)$ but decreased to $40.00 \pm 2.23 \%$ after $48 \mathrm{~h}$ of exposure at the same concentration. The mortality of B. brassicae by $A$. $\operatorname{argyi}(35.00 \pm 3.87 \%)$ was also higher after $24 \mathrm{~h}$ of exposure than that of $24 \mathrm{~h}$ of exposure to C. colocynthis and $C$. indica extracts $(23.33 \pm 2.58 \%$ and $20.00 \pm 2.23 \%$, respectively). The control treatment showed no mortality after $24 \mathrm{~h}$ and $48 \mathrm{~h}$ and negligible mortality $(1.67 \pm 1.29 \%)$ after $72 \mathrm{~h}$, whereas imidacloprid was the positive control and showed the highest $(P<0.05)$ mortality, i.e., $98.33 \pm 2.58,91.67 \pm 2.58$ and $86.67 \pm 1.29 \%$ after $72 \mathrm{~h}, 48 \mathrm{~h}$ and $24 \mathrm{~h}$, respectively.

The results described in Table S2 in the Supplementary File revealed highly significant $(P<0.001)$ model fitness with $(F=101.057,9851.888,59.047,754.712$ and 545.650) intercept, concentration and time. Moreover, the interaction between the mortality (\%) of the aphids versus time and concentration exhibited a highly significant $(P<0.001)$ positive correlation $(F=8.62)$. The two-way analysis of variance provided information regarding the interaction between mortality (\%), treatment and time and highlighted highly significant results $(F=7.25)$. Interaction/correlation between treatments $\times$ concentration $\times$ time and the total variance was firmly trait-specific and significantly correlated with mortality $(P<0.001$ and with $F=2.75)$.

However, data for interaction among plant species, concentration and post-treatment time revealed that the maximum mean mortality based on concentration by different treatments/plant species was recorded at $20 \mathrm{mg} \mathrm{mL}^{-1}$, with $50.56 \pm 7.92 \%$ followed by $43.52 \pm 7.52,35.37 \pm 7.02,28.89 \pm 6.12 \%$ and $20.19 \pm 3.16 \%$ at 15 , 10,5 and $2.5 \mathrm{mg} \mathrm{mL}^{-1}$, respectively. The maximum mean mortality interaction based on time was recorded as $55.00 \pm 6.79 \%$ at $72 \mathrm{~h}$ exposure, followed by $36.35 \pm 6.02$ and $23.89 \pm 5.79 \%$ at 48 and $24 \mathrm{~h}$, respectively. On the other hand, mortality interaction among treatments was evaluated as high (44.13 $\pm 7.14 \%)$ by A. argyi followed by that of $C$. indica and C. colocynthis ( $36.99 \pm 6.67 \%$ and $34.13 \pm 6.53 \%$, respectively). Moreover, the positive control showed a maximum $90.19 \pm 2.09 \%$ mortality, and the negative control showed a minimum mortality of $0.19 \pm 0.18 \%$. Probit analysis showed the $\mathrm{LC}_{50}$ values, slope, chi-square, and fiducial limits at the $95 \%$ confidence interval. Although B. brassicae showed sensitivity to the different plant extracts, A. argyi was the most toxic, followed by C. colocynthis and C. indica, and this mortality response is presented in Table 1.

Contact/aphid dip bioassay. The data presented in Table S3 in the Supplementary File described the mortality (\%) of $B$. brassicae by the contact toxicity method. The results showed that maximum mortality was recorded after $72 \mathrm{~h}$ at $20 \mathrm{mg} \mathrm{mL}^{-1}$. However, the highest mortality caused by the crude extract of $A$. argyi was $93.33 \pm 3.14 \%$, followed by that of $C$. colocynthis and $C$. indica $(83.33 \pm 2.57$ and $81.67 \pm 1.29 \%$, respectively). High mortality after $48 \mathrm{~h}$ of exposure to $15 \mathrm{mg} \mathrm{mL}^{-1}$ was also observed in $A$. argyi $(83.33 \pm 1.29 \%)$, followed by that of C. colocynthis and $C$. indica, which had the same mortality values of $81.67 \pm 3.41 \%$ and $81.67 \pm 1.67 \%$, respectively. Additionally, the mortality of $B$. brassicae by the contact assay was also high for exposure to extracts of $C$. ind$i c a$ even at low concentrations $(78.33 \pm 2.58 \%, 71.67 \pm 3.41 \%$ and $71.67 \pm 3.41 \%$ at concentrations of 10,5 and $2.5 \mathrm{mg} \mathrm{mL}^{-1}$, respectively). The same trend of mortality was observed for C. colocynthis and A. argyi. The negative control treatment showed similar results for mortality in all three experiments for each treatment in both bioassay methods, while imidacloprid showed significantly $(P<0.05)$ high mortality $(98.33 \pm 1.29 \%, 96.67 \pm 2.58 \%$ and $95.00 \pm 2.23 \%$ after $72 \mathrm{~h}, 48 \mathrm{~h}$ and $24 \mathrm{~h}$, respectively) for leaf dip and contact bioassay, which was also the highest mortality.

The results described in Table S4 in the Supplementary File revealed also highly significant $(P<0.001)$ model fitness with $(F=44.42,11152.07,14.66,409.34$ and 67.44) intercept, concentration and time. However, the interaction between mortality $(\%)$ of the aphid versus time and concentration recorded a highly significant $(P<0.001)$ positive correlation $(F=1.58)$. The two-way analysis of variance provided information regarding the interaction between mortality (\%) versus treatment and time highlighted highly significant results $(F=10.07)$. The interaction/correlation between treatments $\times$ concentration $\times$ time and total variance was strongly trait-specific and highlighted significant correlation with mortality $(P<0.001$ with $F=1.79)$. However, data for the interaction among plant species, concentrations and post-treatment time revealed that the maximum mean mortality based 


\begin{tabular}{|c|c|c|c|c|c|c|}
\hline \multirow{2}{*}{$\begin{array}{l}\text { Plants } \\
\text { Extract }\end{array}$} & \multirow{2}{*}{$\begin{array}{l}\text { Time } \\
\text { (h) }\end{array}$} & \multirow{2}{*}{$\begin{array}{l}\mathrm{LC}_{50} \\
\left(\mathrm{mg} \mathrm{mL}^{-1}\right)\end{array}$} & \multicolumn{2}{|c|}{ 95\% F.L. } & \multirow[b]{2}{*}{ Slope \pm SE } & \multirow[b]{2}{*}{$x^{2}$} \\
\hline & & & Lower & Upper & & \\
\hline \multirow{3}{*}{ CCL } & 24 & 2.88 & 0.03 & 4.29 & $0.59 \pm 0.23$ & 0.51 \\
\hline & 48 & 2.35 & 0.62 & 4.01 & $1.01 \pm 0.26$ & 0.77 \\
\hline & 72 & 1.96 & 0.14 & 3.88 & $0.72 \pm 0.24$ & 0.80 \\
\hline \multirow{3}{*}{ CIL } & 24 & 12.1 & 8.86 & 19.3 & $1.07 \pm 0.23$ & 0.06 \\
\hline & 48 & 8.03 & 4.37 & 13.8 & $0.79 \pm 0.24$ & 0.53 \\
\hline & 72 & 2.87 & 0.10 & 5.75 & $0.65 \pm 0.25$ & 0.14 \\
\hline \multirow{3}{*}{ ATL } & 24 & 5.62 & 2.31 & 8.91 & $0.72 \pm 0.22$ & 0.98 \\
\hline & 48 & 4.28 & 1.09 & 7.13 & $0.72 \pm 0.23$ & 0.38 \\
\hline & 72 & 0.22 & 0.01 & 1.31 & $0.58 \pm 0.27$ & 0.30 \\
\hline
\end{tabular}

Table 2. Toxicity against $B$. brassicae after an exposure of 24,48 and 72 hours by the contact/aphid dip method. Note: $\mathrm{LC}_{50}$ (Lethal concentration); S.E. (standard error); $\chi^{2}$ (chi-square); F.L. (fiducial limit). (C. colocynthis), CIL (C. indica) and ATL (A. argyi).

\begin{tabular}{|l|l|l|l|l|l|}
\hline $\begin{array}{l}\text { Peak. } \\
\text { No. }\end{array}$ & RT & Compounds & Area \% & M.F. \\
\hline 1 & 3.16 & Cyclotrisiloxane, hexamethyl- & 3.57 & $\mathrm{C}_{6} \mathrm{H}_{18} \mathrm{O}_{3} \mathrm{Si}_{3}$ & 222.46 \\
\hline 2 & 11.9 & Triamterene & 1.53 & $\mathrm{C}_{12} \mathrm{H}_{11} \mathrm{~N}_{7}$ & 253.26 \\
\hline 3 & 14.6 & Palmitic acid, ethyl ester (Hexadecanoic acid) & 0.98 & $\mathrm{C}_{18} \mathrm{H}_{36} \mathrm{O}_{2}$ \\
\hline 4 & 16.3 & Octasiloxane,1,1,3,3,5,5,7,7,9,9,11,11,13,13,15,15-hexadecamethyl- & 1.25 & $\mathrm{C}_{16} \mathrm{H}_{50} \mathrm{O}_{7} \mathrm{Si}_{8}$ & 579.24 \\
\hline 5 & 16.9 & Tetrasiloxane, decamethyl- & 1.10 & $\mathrm{C}_{10} \mathrm{H}_{30} \mathrm{O}_{3} \mathrm{Si}_{4}$ & 310.68 \\
\hline 6 & 22.6 & Octasiloxane,1,1,3,3,5,5,7,7,9,9,11,11,13,13,15,15-hexadecamethyl & 7.06 & $\mathrm{C}_{16} \mathrm{H}_{50} \mathrm{O}_{7} \mathrm{Si}_{8}$ & 579.24 \\
\hline 7 & 24.7 & Heptasiloxane, 1,1,3,3,5,5,7,7,9,9,11,11,13,13-tetradecamethyl- & 21.3 & $\mathrm{C}_{14} \mathrm{H}_{44} \mathrm{O}_{6} \mathrm{Si}_{7}$ & 505.09 \\
\hline 8 & 25.6 & 5-Methyl-2-phenylindolizine & 17.9 & $\mathrm{C}_{15} \mathrm{H}_{13} \mathrm{~N}$ \\
\hline 9 & 25.8 & Erucylamide & 22.4 & $\mathrm{C}_{18} \mathrm{H}_{35} \mathrm{NO}$ & 207.27 \\
\hline 10 & 26.6 & 4-Nitro-4'-chlorodiphenylsulfoxide & 22.9 & $\mathrm{C}_{12} \mathrm{H}_{8} \mathrm{ClNO}_{2} \mathrm{~S}$ & 265.71 \\
\hline
\end{tabular}

Table 3. Chemical composition of the C. colocynthis extract. M.F. (molecular formula); M.W. (molecular weight); RT (retention time).

on concentration by different treatments/plant species was recorded at $20 \mathrm{mg} \mathrm{mL}^{-1}$, with $74.44 \pm 3.74 \%$ followed by $70 \pm 3.58,63.33 \pm 3.08,56.48 \pm 4.34$ and $47.59 \pm 4.74 \%$ at $15,10,5$ and $2.5 \mathrm{mg} \mathrm{mL}^{-1}$, respectively. The maximum mean mortality interaction based on time was recorded as $66.83 \pm 6.63 \%$ after $72 \mathrm{~h}$ of exposure, followed by $56.27 \pm 6.19 \%$ and $51.51 \pm 6.82 \%$ after 48 and $24 \mathrm{~h}$, respectively. The mortality interaction among treatments was $57.30 \pm 6.31 \%$ by $A$. argyi followed by $62.22 \pm 7.14 \%$ and $55.08 \pm 6.62 \%$ by C. colocynthis and C. indica, respectively. Moreover, the positive control treatment showed a maximum of $95 \pm 1.14 \%$ mortality, and a $0.56 \pm 0.27 \%$ mortality was exhibited by the negative control.

Probit analysis of the data revealed the $\mathrm{LC}_{50}$ values, slope, chi-square, and fiducial limits at the $95 \%$ confidence interval for C. colocynthis, $C$. indica and A. argyi. Mortality response using different plant extracts showed high sensitivity of $B$. brassicae to $A$. argyi followed by $C$. colocynthis and $C$. indica in the contact assay, which is summarized in Table 2.

Gas chromatography-mass spectrophotometry (GC-MS) analysis. The presence of biologically active components from the ethanol extracts of $C$. colocynthis, $C$. indica and A. argyi were evaluated by conducting GC-MS analysis. The principal active compounds, molecular weight ( $\mathrm{g} \mathrm{mol}^{-1}, \mathrm{M}$.W.), molecular formula (M.F.), retention time (R.T.) and peak area (\%) are presented in Tables 3-5. The results of GC-MS analysis of the extracts led to the determination of several biological compounds.

The crude extract of C. colocynthis leaves showed the presence of ten compounds corresponding to $99.99 \%$ of the total extract; however, 4-nitro-4'-chlorodiphenylsulfoxide (22.94\%), erucylamide (22.38\%), heptasiloxane,1,1, 3,3,5,5,7,7,9,9,11,11,13,13-tetradecamethyl- (21.33\%), 5-methyl-2-phenylindolizine (17.85\%), and octasiloxane,1 ,1,3,3,5,5,7,7,9,9,11,11,13,13,15,15-hexadecamethyl- (7.06\%) were the major compounds, and other minor compounds were present in low quantities, with relative peak areas ranging from $0.98-3.57 \%$.

However, the results observed through GC-MS analysis of $C$. indica revealed the presence of twenty compounds corresponding to $97 \%$ of the total extract. Dronabinol (57.29\%), benzenesulfonic acid, 4-nitro- (25.54\%), cannabinol (2.29\%), and cyclobarbital (2.19\%) were the main compounds, while sixteen other minor compounds were reported, with relative peak areas ranging from $0.29-2.00 \%$.

The chemical profiling obtained through GC-MS analysis of $A$. argyi revealed the presence of ten compounds corresponding to $99.80 \%$ of the total extract; however, neodecanoic acid (43.60\%), 2-trimethylsilyl-1,3-dithiane (21.61\%), cyclotrisiloxane, hexamethyl- (10.62\%), 2-isopropenyl-2,3-dihydrofuro[3,2-g]chromen-7-one (6.28\%), and $\mathrm{N}$-isopropyl-3-phenylpropanamide (4.37\%) were the major compounds, and five other minor compounds with lower relative peak areas ranging from $1.44-3.81 \%$ were identified. 


\begin{tabular}{|l|l|l|l|l|l|}
\hline $\begin{array}{l}\text { Peak } \\
\text { No }\end{array}$ & RT & Compounds & Area \% & M.F. & M.W. \\
\hline 1 & 9.91 & Caryophyllene oxide & 0.70 & $\mathrm{C}_{15} \mathrm{H}_{24} \mathrm{O}$ & 220.35 \\
\hline 2 & 10.2 & 3-Methoxybenzyl alcohol & 0.39 & $\mathrm{CH}_{3} \mathrm{O}_{6} \mathrm{H}_{4} \mathrm{CH}_{2} \mathrm{OH}$ & 138.16 \\
\hline 3 & 10.7 & 5H-Naphtho[1,8-bc]thiophen-5-one,3,4-dihydro-2-methyl- & 1.20 & $\mathrm{C}_{12} \mathrm{H}_{10} \mathrm{OS}$ & 202.27 \\
\hline 4 & 10.9 & a-Bisabolol & 0.66 & $\mathrm{C}_{15} \mathrm{H}_{26} \mathrm{O}$ & 222.37 \\
\hline 5 & 11.9 & 2,5-Cyclohexadien-1-one, 2,5-dimethyl-4-[(2,4,5-trimethylphenyl) imino]- & 0.41 & $\mathrm{C}_{17} \mathrm{H}_{19} \mathrm{NO}$ & 253.34 \\
\hline 6 & 16.2 & Phytol & 1.51 & $\mathrm{C}_{20} \mathrm{H}_{40} \mathrm{O}$ & 296.30 \\
\hline 7 & 16.8 & 1,3,4-Trimethoxydibenzofuran & 0.29 & $\mathrm{C}_{15} \mathrm{H}_{14} \mathrm{O}_{6}$ & 290.07 \\
\hline 8 & 17.1 & 9,12,15-Octadecatrienoic acid, ethyl ester, (Z,Z,Z)- & 0.36 & $\mathrm{C}_{20} \mathrm{H}_{4} \mathrm{O}_{2}$ & 306.49 \\
\hline 9 & 18.1 & 2,11-Dimethyl-2,3,4,5,6,7-hexahydro-1H-2-benzazonine & 1.04 & $\mathrm{C}_{14} \mathrm{H}_{24} \mathrm{~N}$ & 203.32 \\
\hline 10 & 18.9 & Acridine & 0.47 & $\mathrm{C}_{13} \mathrm{H}_{9} \mathrm{~N}$ & 179.13 \\
\hline 11 & 19.3 & Benzenesulfonic acid, 4-nitro- & 25.5 & $\mathrm{C}_{6} \mathrm{H}_{5} \mathrm{NO}_{5} \mathrm{~S}$ & 213.17 \\
\hline 12 & 19.4 & $\begin{array}{l}\text { 1H-Indene-4-acetic acid, 6-(1,1-dimethylethyl)-2,3-dihydro-1,1-dimethyl- } \\
\text { methyl ester }\end{array}$ & 1.20 & $\mathrm{C}_{18} \mathrm{H}_{26} \mathrm{O}_{2}$ & 274.40 \\
\hline 13 & 20.1 & $\begin{array}{l}\text { 2H-1-Benzopyran-5-ol, 2-methyl-2-(4-methyl-3-penten-1-yl)-7pentyl- } \\
\text { (Cannabichromene) }\end{array}$ & 0.53 & $\mathrm{C}_{21} \mathrm{H}_{30} \mathrm{O}_{2}$ & 314.46 \\
\hline 14 & 20.2 & 6H-Dibenzo[b,d]pyran-1-ol, 6,6,9-trimethyl-3-propyl- (Cannabivarin) & 1.00 & $\mathrm{C}_{19} \mathrm{H}_{22} \mathrm{O}_{2}$ & 282.38 \\
\hline 15 & 20.9 & Resorcinol, 2-p-mentha-1,8-dien-3-yl-5-pentyl-, (-)-(E)- & 0.53 & $\mathrm{C}_{21} \mathrm{H}_{30} \mathrm{O}_{2}$ & 314.47 \\
\hline 16 & 20.9 & $\begin{array}{l}\text { 2H-1-Benzopyran-5-ol, 2-methyl-2-(4-methyl-3-pentenyl)-7pentyl-, } \\
\text { (+/-)-(Cannabichromene) }\end{array}$ & 2.00 & $\mathrm{C}_{21} \mathrm{H}_{30} \mathrm{O}_{2}$ & 314.47 \\
\hline 17 & 21.7 & Cyclobarbital & 2.19 & $\mathrm{C}_{12} \mathrm{H}_{16} \mathrm{~N}_{2} \mathrm{O}_{3}$ & 236.27 \\
\hline 18 & 22.3 & Dronabinol & 0.40 & $\mathrm{C}_{21} \mathrm{H}_{30} \mathrm{O}_{2}$ & 314.45 \\
\hline 19 & 23.1 & 1,3-Benzenediol, 2-(3,7-dimethyl-2,6-octadienyl)-5-pentyl- & 2.29 & $\mathrm{C}_{21} \mathrm{H}_{26} \mathrm{O}_{2}$ & 310.43 \\
\hline 20 & 23.3 & Cannabinol & & 316.47 \\
\hline
\end{tabular}

Table 4. Chemical composition of the C. indica extract. M.F. (molecular formula); M.W. (molecular weight); RT (retention time).

\begin{tabular}{|l|l|l|l|l|l|}
\hline $\begin{array}{l}\text { Peak } \\
\text { No }\end{array}$ & RT & Compounds & $\begin{array}{l}\text { Area } \\
\%\end{array}$ & M.F. & M.W. \\
\hline 1 & 3.49 & 1,5-Heptadien-4-ol, 3,3,6-trimethyl- & 3.46 & $\mathrm{C}_{10} \mathrm{H}_{18} \mathrm{O}$ & 154.24 \\
\hline 2 & 10.2 & 1,2-Ethanediol, diformate & 1.44 & $\mathrm{C}_{4} \mathrm{H}_{6} \mathrm{O}_{4}$ & 118.08 \\
\hline 3 & 10.5 & Neodecanoic acid & 43.6 & $\mathrm{C}_{10} \mathrm{H}_{20} \mathrm{O}_{2}$ & 172.26 \\
\hline 4 & 10.7 & 2-Trimethylsilyl-1,3-dithiane & 21.6 & $\mathrm{C}_{17} \mathrm{H}_{16} \mathrm{~S}_{2} \mathrm{Si}$ & 192.42 \\
\hline 5 & 16.4 & N-Isopropyl-3-phenylpropanamide & 4.37 & $\mathrm{C}_{12} \mathrm{H}_{17} \mathrm{NO}$ & 191.27 \\
\hline 6 & 16.8 & 2-Isopropenyl-2,3-dihydrofuro[3,2-g]chromen-7-one & 6.28 & $\mathrm{C}_{14} \mathrm{H}_{12} \mathrm{O}_{3}$ & 228.25 \\
\hline 7 & 21.7 & 1-Propanone, 3-(2-hydroxyphenyl)-1,3-diphenyl- & 2.00 & $\mathrm{C}_{21} \mathrm{H}_{18} \mathrm{O}_{2}$ & 302.37 \\
\hline 8 & 22.9 & 2-Ethylacridine & 3.71 & $\mathrm{C}_{15} \mathrm{H}_{13} \mathrm{~N}$ & 207.27 \\
\hline 9 & 23.3 & 5-Methyl-2-phenylindolizine & 2.81 & $\mathrm{C}_{15} \mathrm{H}_{13} \mathrm{~N}$ & 207.27 \\
\hline 10 & 25.7 & Cyclotrisiloxane, hexamethyl- & 10.5 & $\mathrm{C}_{6} \mathrm{H}_{18} \mathrm{O}_{3} \mathrm{Si}_{3}$ & 222.46 \\
\hline
\end{tabular}

Table 5. Chemical composition of the A. argyi extract. M.F. (molecular formula); M.W. (molecular weight); RT (Retention time).

\section{Discussion}

Due to the problems concerning the use of synthetic chemicals for pest management, there is an urgent need to introduce natural products, mainly from plant sources, for use against insect pests, especially $B$. brassicae, which is becoming problematic in cabbage growing areas of the world. Plant extracts or essential oils are commonly applied for pest control measures because of their effectiveness against different life stages of the pests. However, the selected plants (C. colocynthis, C. indica and A. argyi) are naturally repellent to some extent to insect attack, which indicates that they could be suitable candidates against cabbage aphids, $B$. brassicae. An investigation was performed to detect the phytochemical constituents of the extracts of the above-mentioned plants, and their insecticidal activity was evaluated by residual and contact toxicity methods because of the feeding style of aphids ${ }^{33}$.

However, compound extraction from plant parts depends upon the type of plant material and solvent used. High-polarity solvents produced a higher yield than that of low-polarity solvents. In our results, ethanol afforded high extract yields during solvent extraction, which was due to its high polarity. Previously, it was reported that ethanol yielded more than other solvents from leaves of Melastoma malabathricum ${ }^{34}$. Furthermore, a relatively high extract yield from C. colocynthis and C. sativa using ethanol as an extraction solvent was reported ${ }^{35}$.

According to our findings, the mortality of B. brassicae using plant extracts increased with increasing concentrations and exposure periods. However, the physical and chemical properties of the essential oils exhibited 
different persistent levels of insecticidal properties and different action mechanisms ${ }^{36,37}$. It was reported that extracts of Cassia sophera and Ageratum conyzoides against B. brassicae induced mortality that was equivalent to that of the positive control, the synthetic insecticide emamectin benzoate ${ }^{38}$. Moreover, a Mentha piperita extract resulted in maximum insecticidal activity against $B$. brassicae with increased concentration and time exposure ${ }^{39}$. Similarly, essential oil from Cinnamomum zeylannicum was found to be effective against $B$. brassicae, exhibiting 8.3 and $7.4 \mu \mathrm{mL}^{-1} \mathrm{LC}_{50}$ values ${ }^{40}$. The essential oil of another medicinal plant, Elettaria cardamomum, was reported to be effective against this serious pest, exhibiting $79.2 \mu \mathrm{mL}^{-1} \mathrm{LC}_{50}$ value ${ }^{41}$. There are reports that $B$. brassicae was sensitive to 1,8 cineole, a chemical compound found in Laurus nobilis, which at $\mathrm{LD}_{50}$ value of $30 \mu \mathrm{mL} \mathrm{mL}^{-1}$ caused $52 \%$ mortality ${ }^{42}$. Additionally, essential oils isolated from natural plants are usually considered as safe for humans and environment which can be a source of new botanical insecticides. Among some of the plant species, Ocimum basilicum, Mentha piperita, Pimpinella anisum, Mentha pulegium and Foeniculum vulgare have shown outstanding effectiveness against aphids species in both contact and fumigation assays and can thus be considered as active materials for developing new botanical agents ${ }^{43}$. It was also reported that the use of Azadirachta indica oil as a suitable alternative to synthetic chemicals against $B$. brassicae caused a noticeable reduction in their population ${ }^{44}$. All these findings are consistent with our results on the mortality of $B$. brassicae at different concentrations and varying levels of $\mathrm{LC}_{50}$ values.

The results of the studies using the C. colocynthis leaf extract to control B. brassicae are exceptional. However, toxicity of $C$. colocynthis extracts from leaves and fruits against Aphis craccivora was reported ${ }^{45}$. Cucurbitacin E glycosides isolated from C. colocynthis extract showed strong insecticidal effects against Aphis craccivora ${ }^{46}$. Limonene contained by Citrus sinensis was reported to be effective against Myzus persicae at $\mathrm{LC}_{50} 57.7 \mu \mathrm{mL}^{-1}$, whereas its essential oil at a concentration of $3.3 \mu \mathrm{mL}^{-1}$ caused significant mortality of $B$. brassicae $e^{41}$. All these results support our findings of using $C$. colocynthis extract against $B$. brassicae. However, according to our results from the GC-MS analysis, the chemical composition of C. colocynthis was dominated by four of the ten detected compounds. Among these, erucylamide is a high fatty acid amide that can be used as an insecticide, pigment dispersant, ink and paint additive, fibre softener, and in dyes. Octasiloxane hexamethyl from C. colocynthis also exhibits insecticidal properties.

The insecticidal activity of the essential oil of hemp inflorescences against $M$. persicae was reported to be highly toxic, with an $\mathrm{LC}_{50}$ of $3.5 \mathrm{~mL} \mathrm{~L}^{-1}$ and non-toxic to the beneficial organisms ${ }^{26}$. An important compound, (E)-caryophyllene myrecene, and $\alpha$-pinene, contained by C. sativa, showed $98.20 \%$ mortality at $3.50 \mu \mathrm{mL}^{-1}$ of Aulacorthum solani ${ }^{47}$, whereas at the same concentration, similar mortality of $M$. persicae was reported ${ }^{26}$. Previous studies have reported the concentration and time-dependent mortality of Tetranychus urticae and Aulacorthum solani following the use of hemp essential oil, which supported our findings indicating the effectiveness of the hemp (C. sativa) crude extract against B. brassicae aphids ${ }^{47}$. However, among the twenty compounds identified in the crude ethanol extract, caryophylleneonides (sesquiterpenes), $\alpha$-bisabolol and dronabinol ( $\Delta^{9}$-THC) possess insecticidal activities, However, caryophyllene oxide identified from Melaleuca styphelioides exhibited strong aphicidal activities against Aphis spiraecola, Aphis gossypii and M. persicae ${ }^{48}$ while, the other compounds may need to be further explored to determine their biological properties. To date, few studies on the applicability of hemp essential oil against crop pests have been conducted, and the use of hemp essential oil against $B$. brassicae is very rare in the literature.

Similarly, A. argyi is a famous plant commonly found in China, and many species of the genus Artemisia have long been used in traditional Chinese medicines, including Artemisia argyi, Artemisia capillaris and Artemisia annu $a^{49}$. In the present study, the crude ethanol extract from the leaves of $A$. argyi was proven to be highly toxic against B. brassicae. Moreover, four compounds from $A$. argyi, such as camphor, $\beta$-pinene, eucalyptol, and $\beta$-caryophyllene, showed strong toxic effects against adults of Lasioderma serricorne ${ }^{50}$. Other studies have showed that sabinene, and $\beta$-myrecen contained in Artemisia absinthium, caused significant mortality of $M$. persicae at $6.9 \mu \mathrm{lmL} \mathrm{m}^{-1}$ concentration $^{51}$. Similarly, Artemisia seiberi essential oil caused significant mortality of Eriosoma lanigerum at $6.16 \mu \mathrm{mL}^{-1} \mathrm{LD}_{50}$ value $\mathrm{e}^{52}$. Another compound, artemisia ketone, showed significant mortality of $B$. brassicae at $25.0 \mu \mathrm{mL}^{-1}$ concentration ${ }^{53}$. However, according to our results, reported compounds from $A$. argyi leaves were evaluated for the first time for their insecticidal potential. The above-described results supported our findings and clearly demonstrated that the $A$. argyi crude extract exhibited strong and deadly effects against $B$. brassicae, which justified its great potential for controlling this pest.

In the present study, the toxicity of ethanol extracts of the leaves of C. colocynthis, C. indica, and A. argyi against $B$. brassicae were investigated under laboratory conditions, revealing their positive toxicity. A. argyi proved to be the most toxic in both bioassay methods and caused maximum mortality, followed by C. colocynthis and C. indica, in a dose-dependent manner. This insecticidal activity might be due to individual efficacy or the synergistic action of biological compounds present in these plants. A literature survey regarding the potential efficacy of $A$. argyi showed that there are no studies reporting on its use against B. brassicae. Additionally, data on the insecticidal potential of C. colocynthis and C. indica against this serious pest and their GC-MS profiling are limited to a few studies. Thus, the present unique and novel study was conducted for the first time to investigate the insecticidal potential of crude ethanol extracts by residual and contact toxicity methods against $B$. brassicae, a serious pest of cabbage and other field crops.

\section{Conclusions}

The investigations indicated that C. colocynthis, C. indica and A. argyi possess potential botanical agents as an alternative to synthetic pesticides against $B$. brassicae. It can be concluded that, $B$. brassicae, is reasonably sensitive to $A$. argyi followed by C. colocynthis and C. indica as shown in both bioassay methods, even at low concentrations and exposure times. Moreover, in comparison, the contact assay afforded higher mortality than that of the residual assay. Additionally, GC-MS analysis revealed the presence of valuable biologically active compounds 
responsible for aphid mortality. However, further studies are required on the purification and identification of active components responsible for aphid mortality and their evaluations against other insect pests.

\section{Materials and Methods \\ Collection of plant material. Aerial parts of the plants tend to contain a wider variety of compounds, and most of the photosynthesis/respiration occurs in the aerial parts. Additionally, most of the secondary metab- olites from plants are produced in leaves. For this reason, C. colocynthis (Colocynthis) leaves at the 15-20 leaf stage were collected from Bahawalnagar $\left(29^{\circ} 59^{\prime} 34^{\prime \prime} \mathrm{N}, 7^{\circ} 15^{\prime} 13^{\prime \prime} \mathrm{E}\right)$ Punjab, Pakistan from the natural habitat of a desert climate from March to April 2018 and authenticated at the Entomological Research Institute, Faisalabad, Pakistan. This area contains a dry climate with average annual precipitation of $204 \mathrm{~mm}$ and a temperature range of $12.7-45^{\circ} \mathrm{C}$. C. indica (wild hemp) and A. argyi (Chinese mugwort) leaves (10-15 leaf stage) were collected from Shenyang $\left(41^{\circ} 11^{\prime} 43^{\prime \prime} \mathrm{N}, 122^{\circ} 25^{\prime} 48^{\prime \prime} \mathrm{E}\right)$ Liaoning, China, from a temperate climate zone from May to June 2018. This area receives annual precipitation of $266.6 \mathrm{~mm}$, and the temperature ranges from -28.5 to $36.1^{\circ} \mathrm{C}$. The col- lected samples were authenticated at the College of Plant Protection, Department of Pesticides Science, Shenyang Agricultural University, Liaoning P.R., China.}

Preparation of plant material and extraction. The collected leaves were allowed to dry in the shade at room temperature after removing impurities by rinsing in tap water. Dried leaves were ground into a fine powder using an electric blender, and $99.7 \%$ ethanol was used as a solvent for extraction. Approximately $100 \mathrm{~g}$ of ground powder was extracted thrice with $400 \mathrm{~mL}$ of ethanol each time for $72 \mathrm{~h}$ at a constant temperature in an incubator shaker (ZWY-1102C) at $100 \mathrm{rpm}$. After each extraction, the material was filtered through filter paper (Whatman No. 1) and concentrated to reduce the volume by using a rotary evaporator (Buchi Switzerland R-210). Finally, the concentrated filtrate was subjected to drying in a fume hood at $25^{\circ} \mathrm{C}$ for $12 \mathrm{~h}$. The extraction yield was measured for each extract, and the extracts of each plant were combined to obtain a bulk sample and stored in glass-stoppered vials at $4^{\circ} \mathrm{C}$ until use.

Collection and breeding of aphids. Aphids, B. brassicae, were collected from a cabbage field (without pesticidal application) in the experimental field area of Shenyang Agricultural University, China. Aphids were reared on cabbage plants in the lab under controlled conditions of $20 \pm 5^{\circ} \mathrm{C}$ and $45 \pm 5 \%$ R.H., along with a photoperiod of 16:8 (light: dark).

Serial concentration and agar preparation. Tween-20 was used to minimize variations among the treatments effect of any adjuvant material. Fifty millilitres of Tween was dissolved in $950 \mathrm{~mL}$ distilled water by shaking to prepare a $5 \%$ solution. Serial concentrations of crude extract, $2.5,5,10,15$ and $20 \mathrm{mg} \mathrm{mL}^{-1}$ were prepared in the Tween solution one day before beginning the experiment. To prepare the agar, $10-15 \mathrm{~g}$ agar rods were added to one litre of distilled water, boiled for $10 \mathrm{~min}$ with continuous stirring, allowed to cool for $10 \mathrm{~min}$ and was then added to Petri dishes $90 \mathrm{~mm}$ in diameter and $15 \mathrm{~mm}$ deep up to a 3-4 $\mathrm{mm}$ level.

Bioassay study. Two different modes of exposure, residual and contact assays were conducted for the toxicity evaluation. The experiment was replicated five times for each exposure method as well as concentration, and the mortality response was recorded at the exposure times of $24 \mathrm{~h}, 48 \mathrm{~h}$ and $72 \mathrm{~h}$.

Residual toxicity/leaf dip bioassay. Briefly, cabbage leaf discs $5 \mathrm{~cm}$ in diameter were cut with sterilized scissors and dipped for $10 \mathrm{~s}$ in the extracts of varying concentration. Then, the leaf discs were left at room temperature for $10 \mathrm{~min}$ to dry and put in Petri dishes containing agar. Then, twenty aphids at the second instar were carefully transferred onto the leaf disc contained in the Petri dish by a fine-haired brush, and caution was taken to prevent injury to the aphids during their transfer to the leaf disc. Then, a double layer of muslin cloth was placed on each Petri dish and covered with a manually perforated lid to avoid suffocation and escape of the aphids (Fig. 1). The negative control treatment was prepared using a Tween-20 (5\%) solution as described above but without added plant extract. An imidacloprid solution of $20 \% \mathrm{SL}\left(2.5 \mathrm{~mL} \mathrm{~L}^{-1}\right)$ was used as a positive control. All Petri dishes were incubated for $72 \mathrm{~h}$ at $65 \%$ R.H., $25^{\circ} \mathrm{C}$ and with a $16: 8$ (light: dark) photoperiod.

Contact toxicity/aphid dip bioassay. A $30 \mathrm{~mm}$ diameter plastic Petri dish was cut from the basal portion, and the remaining ring was used as the container. A nematode strainer (mesh size $300 \mu \mathrm{m}$ ) was used as a holding cell for aphids during dipping into the plant extracts of varying concentration (Fig. 2). Then, twenty aphids at second instar were isolated from the cabbage plants and dipped in the extracts for $10 \mathrm{~s}$. Each group of dipped aphids was then placed on fresh $5 \mathrm{~cm}$ diameter cut leaf discs on agar-containing Petri dishes. The negative control treatment was prepared using the Tween-20 (5\%) solution as described above but without adding plant extract. An imidacloprid solution of $20 \%$ SL $\left(2.5 \mathrm{~mL} \mathrm{~L}^{-1}\right)$ was used as a positive control. All Petri dishes were incubated for $72 \mathrm{~h}$ at $65 \%$ R.H., $25^{\circ} \mathrm{C}$ and with a 16:8 (light: dark) photoperiod.

Data collection. Mortality data were recorded at the exposure times of $24 \mathrm{~h}, 48 \mathrm{~h}$ and $72 \mathrm{~h}$ by microscopic examination. The response of $B$. brassicae to the crude extracts was observed by needle stimulation, and those individuals who displayed no response were considered dead.

Sample preparation for GC-MS analysis. The solvent-free extract was weighed precisely to $0.005 \mathrm{~g}$ and dissolved in $1 \mathrm{ml}$ of HPLC-grade methanol. Then, the sample was added to a centrifuge tube, and graphitized carbon blacks (GCB) was added $(0.002 \mathrm{mg} /$ tube) and shaken vigorously for one min on a vortex (Vortex Gennic 2, Model G560E Scientific Industries Inc. U.S. A) to remove coloured components. The colourless sample was 


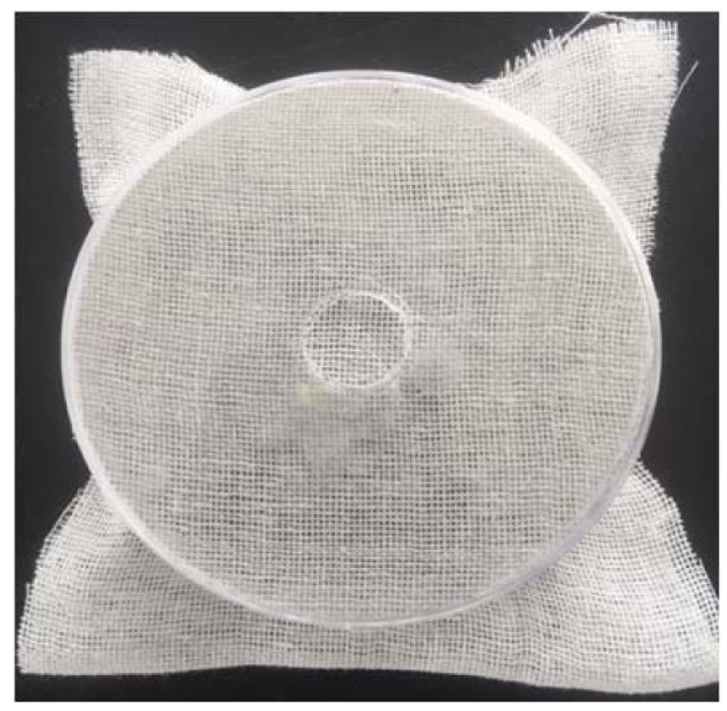

Figure 1. Petri dishes utilized for residual bioassay.

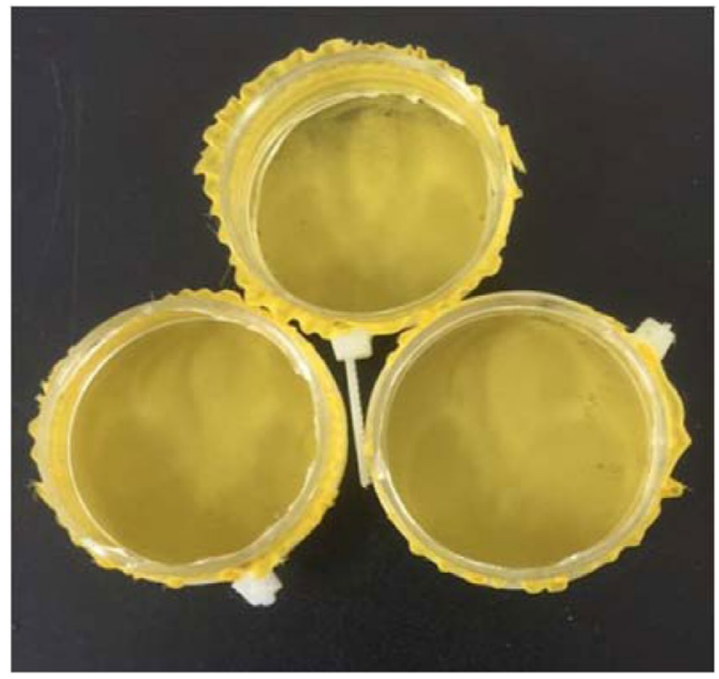

Figure 2. Containers utilized for contact bioassay.

centrifuged for $10 \mathrm{~min}$ at $24^{\circ} \mathrm{C}$ and $12000 \mathrm{rpm}$ (Hitachi Centrifuge CT15RE, Koki Co., Ltd. Japan) to separate the GCB from the sample. The colourless sample was collected by micropipette and transferred to a new centrifuge tube.

Gas chromatography-mass spectrophotometry (GC-MS) analysis. The crude ethanol extracts of $C$. colocynthis, C. indica and A. argyi were analysed via GC-MS using an Agilent 6890-5973N USA gas chromatograph (GC) equipped with an HP1 TG-5MS polydimethylsiloxane capillary column $(30 \mathrm{~m} \times 250 \mu \mathrm{m} \times 0.25 \mu \mathrm{m})$ interfaced with a Hewlett Packard 5973 mass selective detector. Gas chromatographic parameters were as follows: the temperature was fixed at $110^{\circ} \mathrm{C}$ for $2 \mathrm{~min}$ initially and increased to $200^{\circ} \mathrm{C}$ and $280^{\circ} \mathrm{C}$ at increasing rates of $10^{\circ} \mathrm{C} \mathrm{min}^{-1}$ and $5^{\circ} \mathrm{C} \mathrm{min}^{-1}$, respectively. The inlet temperature was $250^{\circ} \mathrm{C}$; a $10: 1$ split ratio was used; MS quadrupole temperature, $150^{\circ} \mathrm{C}$; thermal aux temperature, $285^{\circ} \mathrm{C}$; ionization current, $60 \mu \mathrm{A}$; MS temperature, $230^{\circ} \mathrm{C}$; MS scan range, $\mathrm{m} / \mathrm{z} 40-450$; ionization energy, $70 \mathrm{eV}$; carrier gas, helium with flow rate, $1.0 \mathrm{~mL} \mathrm{~min}^{-1}$. Compounds were identified by comparison of the GC-MS mass spectra with those in the literature or in databases at Wiley/NIST.98.1 ${ }^{54,55}$. The relative abundance of each compound was assessed based on the raw data peak areas in the spectra with no response factor correction from the FID.

Data analysis. All recorded mortality data were subjected to two-way analysis of variance (ANOVA) for calculating the interaction among plants, concentration and post-treatment time, while the mean difference between treatments was calculated for the significance test by Tukey's HSD at the $P=0.05$ level. All statistical processes were administered by different statistical packages with IBM-SPSS version 25.0 software, while LC $_{50}$ values, slope, chi-square values and fiducial limits were calculated by the EPA Probit analysis program version 1.5. 
Received: 22 September 2019; Accepted: 17 December 2019; Published online: 16 January 2020

\section{References}

1. Kessing, J. \& Mau, R. Cabbage aphid, Brevicoryne brassi-cae (Linnaeus). Crop Knowledge Master. Department of Entomology, Honolulu, Hawaii.(2 October 2013) (1991).

2. Munthali, D. Evaluation of cabbage varieties for resistance to the cabbage aphid. African Entomology 17, 1-8 (2009).

3. Opfer, P. \& McGranth, D. Oregon vegetables, cabbage aphid and green peach aphid. Department of Horticulture. Oregon State University, Corvallis, OR. Disponível em:.[Acesso em: 29. iii. 2017] (2013).

4. Chivasa, S., Ekpo, E. \& Hicks, R. New hosts of Turnip mosaic virus in Zimbabwe. Plant pathology 51 (2002).

5. Griffin, R. \& Williamson, J. Cabbage, Broccoli \& Other Cole Crop Insect Pests HGIC 2203, Home\& Garden Information Center. Clemson Cooperative Extension. Clemson University, Clemson, SC.(2 October 2013 (2012).

6. Blackman, R. L. \& Eastop, V. F. Aphids on the world's herbaceous plants and shrubs, 2 volume set. (John Wiley \& Sons, 2008).

7. Jabbar, A. S. \& Sasdoon, S. M. Ecological Studies of Certain Aphid Species and their Associated Predators on Wheat Plants at Qadisiyah Distract, Iraq. Indian Journal of Public Health Research \& Development 10 (2019).

8. McKone, T. E. et al. Merging models and biomonitoring data to characterize sources and pathways of human exposure to organophosphorus pesticides in the Salinas Valley of California. Environmental science \& technology 41, 3233-3240 (2007).

9. Lu, C., Chang, C.-H., Palmer, C., Zhao, M. \& Zhang, Q. Neonicotinoid residues in fruits and vegetables: An integrated dietary exposure assessment approach. Environmental science \& technology 52, 3175-3184 (2018).

10. Lozowicka, B. et al. Studies of pesticide residues in tomatoes and cucumbers from Kazakhstan and the associated health risks. Environmental monitoring and assessment 187, 609 (2015).

11. Kazem, M. G. \& El-Shereif, S. Toxic effect of capsicum and garlic xylene extracts in toxicity of boiled linseed oil formulations against some piercing sucking cotton pests. American-Eurasian Journal of Agricultural and Environmental Science 8, 390-396 (2010).

12. Fetoh, B. E.-S. A. \& Asiry, K. A. Toxicological and larvicidal activities of Alzanzalakhet, Melia azedarach against cucurbit fly, Dacus ciliatus at Hail Province in Saudi Arabia. Toxicological \& Environmental Chemistry 94, 1350-1356, https://doi.org/10.1080/0277224 8.2012.705466 (2012).

13. Koul, O., Walia, S. \& Dhaliwal, G. Essential oils as green pesticides: potential and constraints. Biopestic Int 4, 63-84 (2008).

14. Isman, M. B. Botanical insecticides, deterrents, and repellents in modern agriculture and an increasingly regulated world. Annu. Rev. Entomol. 51, 45-66 (2006).

15. Naumann, K. \& Isman, M. B. Toxicity of a neem (Azadirachta indica A. Juss) insecticide to larval honey bees. American Bee Journal (1996).

16. Rahman, S. S. et al. Ethanolic extract of melgota (Macaranga postulata) for repellency, insecticidal activity against rice weevil (Sitophilus oryzae). African Journal of Biotechnology 6 (2007).

17. Batta, Y. Control of rice weevil (Sitophilus oryzae L., Coleoptera: Curculionidae) with various formulations of Metarhizium anisopliae. Crop Protection 23, 103-108 (2004).

18. Park, H.-J. et al. Insecticidal alkaloids on aphids from Corydalis turtschaninovii tubers. Journal of the Korean Society for Applied Biological Chemistry 54, 345-352 (2011).

19. Kim, S. K. et al. Insecticidal activity of rhamnolipid isolated from Pseudomonas sp. EP-3 against green peach aphid (Myzus persicae). Journal of agricultural and food chemistry 59, 934-938 (2010).

20. Rashid, T., Chen, J. \& McLeod, P. Toxicity of newly isolated piperideine alkaloids from the red imported fire ant, Solenopsis invicta Buren, against the green peach aphid, Myzus persicae (Sulzer). Advances in Entomology 1, 20 (2013).

21. Baidoo, P. \& Adam, J. The effects of extracts of Lantana camara (L.) and Azadirachta indica (A. Juss) on the population dynamics of Plutella xylostella, Brevicoryne brassicae and Hellula undalis on cabbage. (2012).

22. Kibrom, G. et al. Field evaluation of aqueous extract of Melia azedarach Linn. seeds against cabbage aphid, Brevicoryne brassicae Linn.(Homoptera: Aphididae), and its predator Coccinella septempunctata Linn.(Coleoptera: Coccinellidae). Archives of phytopathology and plant protection 45, 1273-1279 (2012).

23. Birhanu, M., Awoke, Y., Tahgas, A. \& Raja, N. Efficacy of Melia azadarach and Mentha piperita plant extracts against cabbage aphid, Brevicoryne brassicae (Homoptera: Aphididae). World Applied Sciences Journal 12, 2150-2154 (2011).

24. McPartland, J. M. Cannabis as repellent and pesticide. Journal of the International Hemp Association 4, 89-94 (1997).

25. Pellati, F. et al. New methods for the comprehensive analysis of bioactive compounds in Cannabis sativa L.(hemp). Molecules 23, 2639 (2018).

26. Benelli, G. et al. The essential oil from industrial hemp (Cannabis sativa L.) by-products as an effective tool for insect pest management in organic crops. Industrial crops and products 122, 308-315 (2018).

27. Seenivasan, S., Jayakumar, M., Raja, N. \& Ignacimuthu, S. Effect of bitter apple, Citrullus colocynthis (L.) Schrad seed extracts against pulse beetle, Callosobruchus maculatus Fab.(Coleoptera: Bruchidae). Entomon-Trivandrum 29, 81-84 (2004).

28. Asiry, K. A. Aphidicidal activity of different aqueous extracts of bitter apple Citrullus colocynthis (L.) against the bird cherry-oat aphid, Rhopalosiphum padi (L.)(Homoptera: Aphididae) under laboratory conditions. J. Anim. Plant. Sci 25, 456-462 (2015).

29. Jeon, J.-H. \& Lee, H.-S. Biofunctional constituent isolated from Citrullus colocynthis fruits and structure-activity relationships of its analogues show acaricidal and insecticidal efficacy. Journal of agricultural and food chemistry 62, 8663-8667 (2014).

30. Ming-gao, S. Research on the Bioactivity of Argy wormwood [J]. Journal of Anhui Agricultural Sciences 20 (2008).

31. Abdelgaleil, S. A., Abbassy, M. A., Belal, A.-S. H. \& Rasoul, M. A. A. Bioactivity of two major constituents isolated from the essential oil of Artemisia judaica L. Bioresource technology 99, 5947-5950 (2008).

32. Pitarokili, D., Tzakou, O., Loukis, A. \& Harvala, C. Volatile metabolites from Salvia fruticosa as antifungal agents in soilborne pathogens. Journal of agricultural and food chemistry 51, 3294-3301 (2003).

33. Pedigo, L. P. \& Rice, M. E. Entomology and pest management. (Waveland Press, 2014).

34. Awang, M. A. et al. Comparison of different solvents on the extraction of Melastoma malabathricum leaves using soxhlet extraction method. Der Pharm Lett 8, 153-157 (2017).

35. Ahmed, M. et al. Phytochemical screening, Total phenolics and Flavonoids content and Antioxidant activities of Citrullus colocynthis L. and Cannabis sativa L. Vol. 17(3) (Applied Ecology and Environmental Research, 2019).

36. Bailen, M. et al. Chemical composition and biological effects of essential oils from Artemisia absinthium L. cultivated under different environmental conditions. Industrial crops and products 49, 102-107 (2013).

37. Benelli, G., Pavela, R., Canale, A. \& Mehlhorn, H. Tick repellents and acaricides of botanical origin: a green roadmap to control tick-borne diseases? Parasitology Research 115, 2545-2560 (2016).

38. Amoabeng, B. W. et al. Tri-trophic insecticidal effects of African plants against cabbage pests. PloS one 8, e78651 (2013).

39. Mersha, W. et al. Repellent and insecticidal activity of Mentha piperita (L.) plant extracts against cabbage aphid [Brevicoryne brassicae Linn.(Homoptera: Aphididae)]. American-Eurasian Journal of Scientific Research 9, 150-156 (2014).

40. Hasanshahi, G. et al. Fumigant toxicity and nymph production deterrence effect of three essential oils against two aphid species in the laboratory condition. Journal of Essential Oil Bearing Plants 19, 706-711 (2016).

41. Jahan, F., Abbasipour, H. \& Hasanshahi, G. Fumigant toxicity and nymph production deterrence effect of five essential oils on adults of the cabbage aphid, Brevicoryne brassicae L.(Hemiptera: Aphididae). Journal of Essential Oil Bearing Plants 19, 140-147 (2016). 
42. Kahan, A. et al. Toxic activity of laurel essential oil and cineole on Brevicoryne brassicae L. over cabbage. Revista De La Facultad De Ciencias Agrarias 40, 41-48 (2008).

43. Ikbal, C. \& Pavela, R. Essential oils as active ingredients of botanical insecticides against aphids. Journal of Pest Science, 1-16 (2019).

44. Pissinati, A. \& Ventura, M. U. Control of Cabbage Aphid, Brevicoryne brassicae Using Kaolin and Neern Oil. Journal of Entomology 12, 48-54 (2015).

45. Farghaly, S., Torkey, H. \& Abou-Yousef, H. Natural extracts and their chemical constituents in relation to toxicity against whitefly (Bemisia tabaci) and aphid (Aphis craccivora). Australian Journal of Basic and Applied Sciences 3, 3217-3223 (2009).

46. Torkey, H., Abou-Yousef, H., Abdel Azeiz, A. \& Farid, H. Insecticidal effect of cucurbitacin E glycoside isolated from Citrullus colocynthis against Aphis craccivora (2009).

47. Górski, R., Sobieralski, K. \& Siwulski, M. The effect of hemp essential oil on mortality Aulacorthum solani Kalt. and Tetranychus urticae Koch. Ecological Chemistry and Engineering S 23, 505-511 (2016).

48. Albouchi, F., Ghazouani, N., Souissi, R., Abderrabba, M. \& Boukhris-Bouhachem, S. Aphidicidal activities of Melaleuca styphelioides Sm. essential oils on three citrus aphids: Aphis gossypii Glover; Aphis spiraecola Patch and Myzus persicae (Sulzer). South African journal of botany 117, 149-154 (2018).

49. You, C. et al. Identification of repellent and insecticidal constituents from Artemisia mongolica essential oil against Lasioderma serricorne. Journal of Chemistry 2015 (2015).

50. Zhang, W.-J. et al. Bioactivity of essential oil of Artemisia argyi Lévl. et Van. and its main compounds against Lasioderma serricorne. Journal of oleo science 63, 829-837 (2014).

51. Czerniewicz, P., Chrzanowski, G., Sprawka, I. \& Sytykiewicz, H. Aphicidal activity of selected Asteraceae essential oils and their effect on enzyme activities of the green peach aphid, Myzus persicae (Sulzer). Pesticide biochemistry and physiology 145, 84-92 (2018).

52. Ateyyat, M., Abdel-Wali, M. \& Al-Antary, T. Toxicity of five medicinal plant oils to woolly apple aphid, Eriosoma lanigerum (Homoptera: Aphididae). Aust J Basic Appl Sci 6, 66-72 (2012).

53. Motazedian, N., Aleosfoor, M., Davoodi, A. \& Bandani, A. R. Insecticidal activity of five medicinal plant essential oils against the cabbage aphid, Brevicoryne brassicae. Journal of crop protection 3, 137-146 (2014).

54. Joulain, D. \& König, W. A. The atlas of spectral data of sesquiterpene hydrocarbons. (EB-Verlag, 1998).

55. Sparkman, O. D. Identification of essential oil components by gas chromatography/quadrupole mass spectroscopy Robert P. Adams. Journal of the American Society for Mass Spectrometry 16, 1902-1903 (2005).

\section{Acknowledgements}

The financial support provided by the National Key Research \& Development (R\&D) Programme of China (2016YFD0200500) is greatly acknowledged.

\section{Author contributions}

M.J., Q.P., Z.G. and Y.L. conceived the experiment, M.A., A.S. and A.J. conducted the experiment, J.S., D.H., M.F.I. Y.Z., H.G., R.A., Y.D. and W.W. analysed the results. M.A. wrote the manuscript. All authors reviewed the manuscript.

\section{Competing interests}

The authors declare no competing interests.

\section{Additional information}

Supplementary information is available for this paper at https://doi.org/10.1038/s41598-019-57092-5.

Correspondence and requests for materials should be addressed to Q.P. or M.J.

Reprints and permissions information is available at www.nature.com/reprints.

Publisher's note Springer Nature remains neutral with regard to jurisdictional claims in published maps and institutional affiliations.

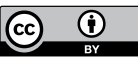

Open Access This article is licensed under a Creative Commons Attribution 4.0 International License, which permits use, sharing, adaptation, distribution and reproduction in any medium or format, as long as you give appropriate credit to the original author(s) and the source, provide a link to the Creative Commons license, and indicate if changes were made. The images or other third party material in this article are included in the article's Creative Commons license, unless indicated otherwise in a credit line to the material. If material is not included in the article's Creative Commons license and your intended use is not permitted by statutory regulation or exceeds the permitted use, you will need to obtain permission directly from the copyright holder. To view a copy of this license, visit http://creativecommons.org/licenses/by/4.0/.

(c) The Author(s) 2020 